\title{
A Simple Chromatographic Procedure for the Detection of Cyclized Archaebacterial Glycerol-Bisdiphytanyl-Glycerol Tetraether Core Lipids
}

\author{
By A. TRINCONE, ${ }^{1}$ M. DE ROSA, ${ }^{1,2}$ A. GAMBACORTA ${ }^{1}$, \\ V. LANZOTTI, ${ }^{1}$ B. NICOLAUS, ${ }^{1}$ J. E. HARRIS ${ }^{3}$ AND W. D. GRANT ${ }^{4 *}$ \\ ${ }^{1}$ Istituto di Chimica di Molecole di Interesse Biologico, del Consiglio Nazionale delle Ricerche, \\ 80072-Arco Felice, via Toiano 6, Italy \\ ${ }^{2}$ Istituto di Biochimica delle Macromolecole, Universita' di Napoli, Napoli, Italy \\ ${ }^{3}$ Food Research Institute, Colney Lane, Norwich NR4 7UA, UK \\ ${ }^{4}$ Department of Microbiology, University of Leicester, Leicester LE1 7RH, UK
}

(Received 26 May 1988)

\begin{abstract}
Archaebacterial glycerol-bisdiphytanyl-glycerol tetraether core lipids containing from one to eight cyclopentane rings could be resolved from each other and from the parent uncyclized $\mathrm{C}_{40}, \mathrm{C}_{40}$ lipid by TLC. The core lipids of examples from the genera Methanobacterium, Methanobrevibacter, Methanogenium and Methanoplanus did not contain cyclized forms of glycerol-bisdiphytanyl-glycerol tetraethers, whereas the core lipids of Methanosarcina barkeri contained glycerol-bisdiphytanyl-glycerol tetraethers with from one to three cyclopentane rings in each $\mathbf{C}_{\mathbf{4 0}}$ isopranoid chain.
\end{abstract}

\section{INTRODUCTION}

All membrane lipids of archaebacteria characterized to date are based on saturated isopranoid ethers formed by condensation of glycerol, or more complex polyols, with isopranoid alcohols containing 20,25 or 40 carbon atoms (De Rosa et al., 1986a). Most halophilic archaebacteria have membrane lipids based exclusively on 2,3 di-O-phytanyl-sn-glycerol $\left(\mathrm{C}_{20}, \mathrm{C}_{20}\right)$, although a few isolates, notably the alkaliphiles, also have significant amounts of $\mathrm{C}_{25}$ (sesterterpanyl) chains as $C_{20}, C_{25}$ glycerol diethers (De. Rosa et al., 1982, 1983a). The situation is more complex for methanogenic and thermophilic archaebacteria, since, in most cases, the membranes have a significant component of glycerol-bisdiphytanyl-glycerol tetraethers. These are formed by dimerization of diphytanyl diethers, where head-to-head linkage between the terminal methyls occurs.

Methanogen core lipid structures are particularly diverse, in that in some isolates, glycerol may be replaced by a tetritol, both in the core lipid structures (De Rosa et al., 1986 b) and in complex lipids (Ferrante et al., 1987). Furthermore, one isolate has a macrocyclic diether with a 36-member ring, which originates from the condensation of a glycerol, in the 2,3-sn-configuration, with the 3,7,11,15,18,22,26,30-octamethyldotriacontane-1-32-diol (Comita \& Gagosian, 1983).

Thermophilic archaebacteria of the genera Desulfurococcus, Thermoproteus, Thermofilum and Pyrodictium have ether lipids based on $\mathrm{C}_{20}$ and $\mathrm{C}_{40}$ chains (Stetter et al., 1983; Zillig et al., 1981, 1982, 1983) whereas Thermococcus celer contains only $C_{20}, C_{20}$ lipids (De Rosa et al., 1987). In Sulfolobus spp. the lipids are based on $\mathrm{C}_{40}, \mathrm{C}_{40}$ tetraethers, but there are two classes; one class consists of glycerol dialkyl glycerol tetraethers (GDGT), while the second differs from the first in that, nonitol, a nine-carbon polyol, replaces one of the glycerols (GDNT). These $C_{40}, C_{40}$ lipids have the additional feature of containing up to four cyclopentane rings in each $\mathrm{C}_{40}$ chain. The degree of cyclization depends on the growth temperature of the organism (De Rosa et al., 1986a).

Abbreviations: GDGT, glycerol dialkyl glycerol tetraethers; GDNT, glycerol dialkyl nonitol tetraethers. 
Cyclization of $\mathrm{C}_{40}, \mathrm{C}_{40}$ core lipids has only been found in one methanogen to date (De Rosa et $a l$., $1986 \mathrm{~b}$ ), but detailed structural analyses of $\mathrm{C}_{40}, \mathrm{C}_{40}$ lipids have only rarely been done (De Rosa et al., 1986b; Kramer et al., 1987; Kushwaha et al., 1981; Comita \& Gagosian, 1983). The resolution and identification of cyclized forms currently involves a lengthy combination of column chromatography and HPLC, or GLC of the hydrocarbon chains after hydrolysis and derivatization (De Rosa et al., 1983b; Tornabene \& Langworthy, 1979; Makula \& Singer, 1978). We report here a simple TLC procedure for the resolution of different cyclized forms of GDGT and the use of this procedure to survey the core lipids of a number of different methanogens.

\section{METHODS}

Micro-organisms and culture conditions. Details of methanogens are shown in Table 1. Growth conditions were as previously described (Grant et al., 1985). Sulfolobus solfataricus MT-4 was grown in the standard medium at $87^{\circ} \mathrm{C}$ as previously described (De Rosa et al., 1975). Cells were harvested at the stationary phase of growth and freezedried.

Extraction and isolation of lipids. Polar lipids were extracted by the procedure of Bligh \& Dyer (1959) as modified by Minnikin et al. (1979). Core lipids were extracted into chloroform or hexane, after hydrolysis of complex lipids by acid methanolysis (Ross et al., 1985). Purified samples of 2,3-di-O-phytanyl-sn-glycerol $\left(\mathrm{C}_{20}, \mathrm{C}_{20}\right.$ diether), 3-Ophytanyl-sn-glycerol $\left(C_{20}\right.$ monoether), tetritol $C_{20}, C_{20}$ diether, uncyclized $C_{40}, C_{40}$ tetraether and the glycerolbisdiphytanyl-glycerol tetraether $\left(\mathrm{C}_{40}, \mathrm{C}_{40}\right.$ tetraether) fraction from Methanosarcina barkeri (De Rosa et al., 1986 b) were available for comparison by TLC.

$T L C$. This was done on $0.25 \mathrm{~mm}$ layers of silica gel F 254 (Merck), activated by heating at $100^{\circ} \mathrm{C}$ for $2 \mathrm{~h}$. The solvent was $n$-hexane/ethyl acetate $(7: 3, v / v)$, single development. Compounds were detected by spraying with $0.1 \%(w / v) \mathrm{Ce}\left(\mathrm{SO}_{4}\right)_{2}$ in $1 \mathrm{M}-\mathrm{H}_{2} \mathrm{SO}_{4}$ followed by heating at $150^{\circ} \mathrm{C}$ for $5 \mathrm{~min}$.

\section{RESULTS AND DISCUSSION}

In a previous study (Grant $e t$ al., 1985) the core lipids of a considerable number of different methanogens were analysed by TLC. Glycerol ethers with 20,25 and 40 carbon atoms were detected, along with a number of new structures. In a later study, two of these new structures from $M s$. barkeri were characterized as a $\mathrm{C}_{20}$ glycerol monoether and $\mathrm{C}_{20}, \mathrm{C}_{20}$ tetritol diether (De Rosa et al., 1986b). Furthermore, the $C_{40}, C_{40}$ tetraether core lipids of this organism were shown to be of the GDGT class and to contain from one to three cyclopentane rings (De Rosa $e t$ $a l ., 1986 b$ ). To date, Ms. barkeri is the only known methanogen known to possess cyclized core lipids; indeed this organism contains no uncyclized $\mathrm{C}_{40}, \mathrm{C}_{40}$ lipids. The TLC system used by

Table 1. Core lipids occurring in a range of methanogens

Culture
collection no.*
DSM 862
DSM 1535
DSM 1053
DSM 861
DSM 1093
DSM 744
DSM 1224
DSM 1537
DSM 2095
DSM 1497
DSM 1498
DSM 2373
DSM 2279
DSM 800

\section{Organism}

Methanobacterium bryantii

Methanobacterium formicicum

Methanobacterium thermoautotrophicum

Methanobrevibacter smithii

Methanobrevibacter ruminantium

Methanobrevibacter arboriphilicus

Methanococcus vannielii

Methanococcus voltae

Methanococcus thermolithotrophicus

Methanogenium cariaci

Methanogenium marisnigri

Methanogenium thermophilicum

Methanoplanus limicola

Methanosarcina barkeri

$\begin{array}{lc}\mathrm{C}_{40}, \mathrm{C}_{40} & \mathrm{C}_{20}, \mathrm{C}_{20} \dagger \\ \text { Acyclic } & + \\ \text { Acyclic } & + \\ \text { Acyclic } & + \\ \text { Acyclic } & + \\ \text { Acyclic } & + \\ \text { Acyclic } & + \\ - & + \\ - & + \\ - & + \\ \text { Acyclic } & + \\ \text { Acyclic } & + \\ \text { Acyclic } & + \\ \text { Acyclic } & + \\ \text { Cyclic } & +\end{array}$

-, No $\mathrm{C}_{40}, \mathrm{C}_{40}$ components present.

* DSM, Deutsche Sammlung von Mikroorganismen und Zellkulturen, Braunschweig, FRG.

+ Data from Grant et al. (1985).

$\$$ Also contains $C_{20}$ glycerol monoether, $C_{25}, C_{20}$ glycerol diether and $C_{20}, C_{20}$ tetritol diether (De Rosa et al., $1986 b)$. 


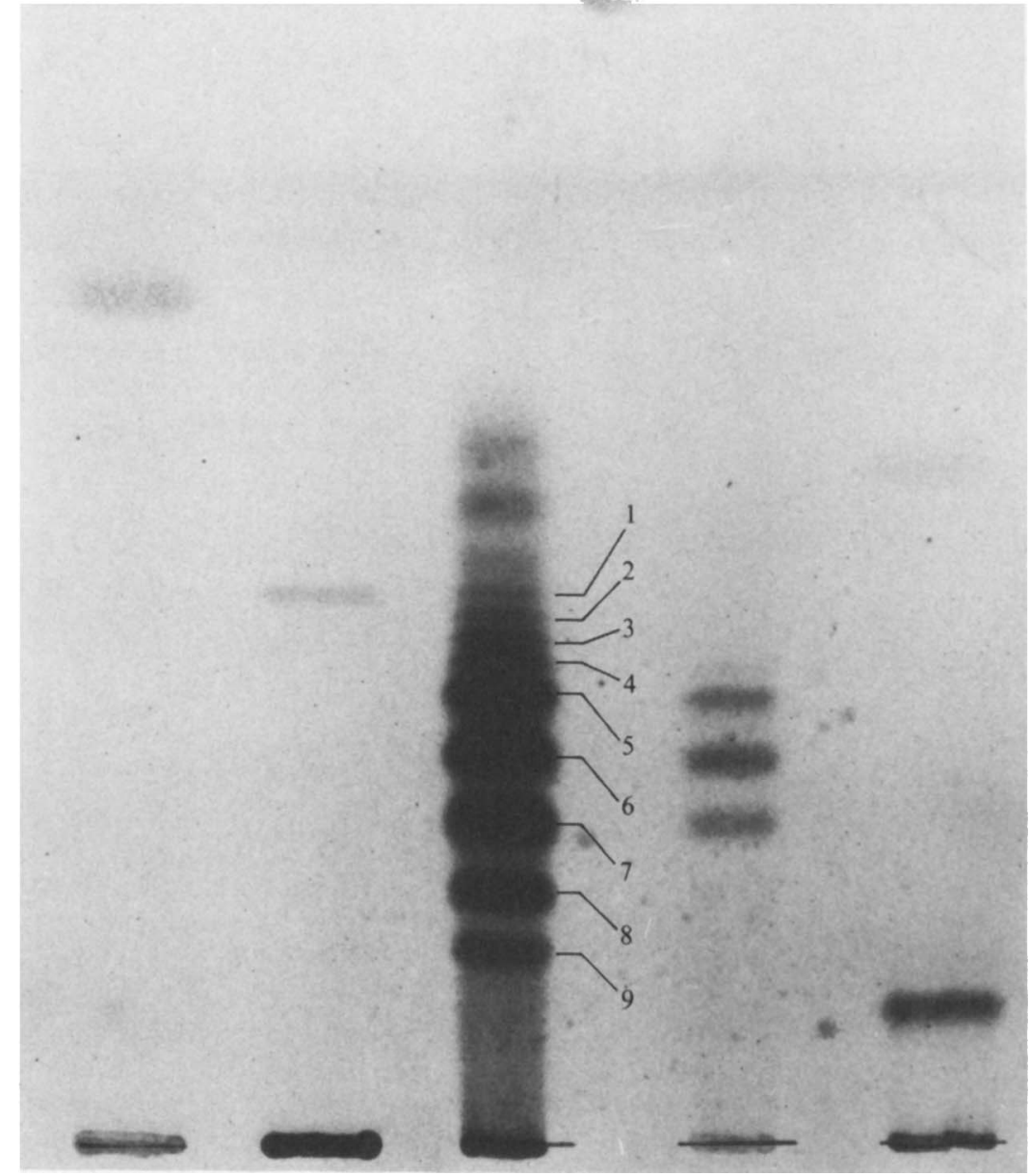

Fig. 1. TLC of core ether lipids using a simple development system ( $n$-hexane/ethyl acetate, $7: 3, v / v)$. Lanes: A, 2,3-di-O-phytanyl-sn-glycerol; $B$, uncyclized $C_{40}, C_{40}$ derivative of GDGT; $C$, core lipids of $S$. solfataricus (structures of compounds $1-9$ are indicated in Fig. 2); D, $\mathrm{C}_{40}, \mathrm{C}_{40}$ lipids of Ms. barkeri; $\mathrm{E}, 3-0$-phytanyl-sn-glycerol (lower band) and tetritol $\mathrm{C}_{20}, \mathrm{C}_{20}$ diether (upper band).

Grant et al. (1985) does not resolve cyclized forms of $\mathrm{C}_{40}, \mathrm{C}_{40}$ core lipids from uncyclized forms and it is, therefore, not clear whether cyclized $\mathrm{C}_{40}, \mathrm{C}_{40}$ core lipids are present in the hydrolysed lipid extracts of those methanogens that have not been subject to detailed chemical characterization.

Chromatography of core lipid extracts on $0.25 \mathrm{~mm}$ layers of silica gel F 254 in $n$-hexane/ethyl acetate $7: 3(\mathrm{v} / \mathrm{v})$ resolved both uncyclized GDGT and the eight different cyclized variations of this $\mathrm{C}_{40}, \mathrm{C}_{40}$ tetraether lipid found in the core lipids of $S$. solfataricus (Fig. 1). The structures of these compounds are shown in Fig. 2. Purified samples (De Rosa et al., 1983b) were used to confirm the separation order shown in Fig. 1. A purified $\mathrm{C}_{40}, \mathrm{C}_{40}$ core lipid fraction from $M s$. barkeri was readily resolved into the three fractions corresponding to the cyclized forms of GDGT containing four, five or six cyclopentane rings, characterized in the previous study (De Rosa et al., 1986b). Samples of $C_{20}, C_{20}$ diether, tetritol $C_{20}, C_{20}$ diether and $C_{20}$ monoether have different $R_{F}$ values and were clearly distinct from $\mathrm{C}_{40}, \mathrm{C}_{40}$ tetraethers (Fig. 1). GDNT ethers remained at the origin using this solvent system.

Table 1 shows the results of a survey of the core lipids of several different methanogens using this TLC procedure. Of the strains tested, only Ms. barkeri possessed cyclized GDGT core 

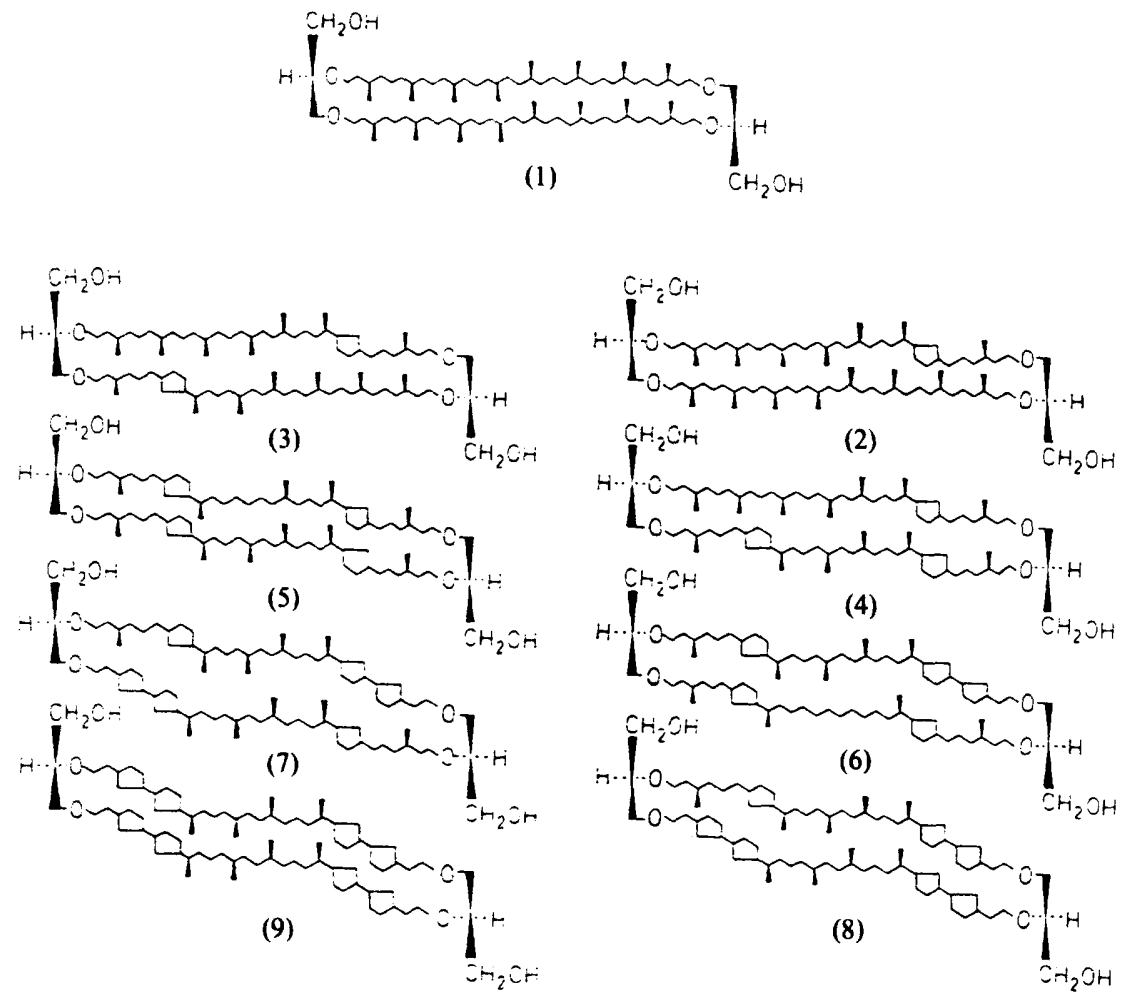

Fig. 2. Structures of $\mathrm{C}_{40}, \mathrm{C}_{40}$ core lipids (GDGT type), the backbone of complex lipids of thermophilic archaebacteria. The numbers 1-9 correspond to the bands in Fig. 1, lane C.

lipids. Included in the survey were Methanobacterium thermoautotrophicum and Methanobrevibacter arboriphilicus, whose complex lipids have been extensively characterized as $\mathrm{C}_{20}, \mathrm{C}_{20}$ diethers and uncyclized $C_{40}, C_{40}$ (GDGT) derivatives (Kramer et al., 1987; Morii et al., 1986). This preliminary survey suggests that cyclization of $\mathrm{C}_{40}, \mathrm{C}_{40}$ tetraether lipids is likely to be uncommon amongst methanogenic archaebacteria that contain $\mathrm{C}_{40}, \mathrm{C}_{\mathbf{4 0}}$ tetraether lipids of the GDGT class. This supports and extends the results of the early surveys of Tornabene \& Langworthy (1979) and Makula \& Singer (1978).

The pattern of complex lipids and core lipids of archaebacteria has some value in the taxonomy of the group (Ross et al., 1985; Langworthy \& Pond, 1986; Grant et al., 1985). The use of this simple TLC procedure for the detection of cyclized GDGT core lipids extends the range of techniques that can readily be applied in non-specialist laboratories.

We thank Dr M.R. Vaccaro and Mr G. Pinch for their technical assistance.

\section{REFERENCES}

BLIGH, E. G. \& DYER, W. J. (1959). A rapid method of total lipid extraction and purification. Canadian Journal of Biochemistry and Physiology 37, 911-917.

Comita, P. B. \& GAgosinN, R. B. (1983). Structural elucidation of a unique macrocyclic membrane lipid from a new, extremely thermophilic deep-sea hydrothermal vent archaebacterium, Methanococcus jannaschii. Journal of Biological Chemistry 259, 15234-15241.

De Rosa, M., Gambacorta, A. \& Bu'Lock, J. D. (1975). Extremely thermophilic acidophilic bacteria convergent with Sulfolobus solfataricus. Journal of General Microbiology 86, 156-164.

De Rosa, M., Gambacorta, A., Nicolaus, B., Ross, H. N. M., Grant, W. D. \& Bu'Lock, J. D. (1982). An asymmetric diether lipid from alkaliphilic halophiles. Journal of General Microbiology 128, 343-348.

De Rosa, M., Gambacorta, A., Nicolaus, B. \& GraNt, W. D. (1983a). A $C_{25}, C_{25}$ diether core lipid from archaebacterial halophiles. Journal of General Microbiology 129, 2333-2337. 
De Rosa, M., Gambacorta, A., Nicolaus, B., ChAPPE, B. \& ALBRECHT, P. (1983b). Isoprenoid ethers: backbone of complex lipids of the archaebacterium Sulfolobus solfataricus. Biochimica et biophysica acta 753, 249-256.

De Rosa, M., Gambacorta, A. \& Gliozzi, A. (1986a). Structure, biosynthesis and physicochemical properties of archaebacterial lipids. Microbiological Reviews 50, 70-80.

De Rosa, M., Gambacorta, A., Lanzotti, V., Trincone, A., Harris, J. E. \& Grant, W. D. $(1986 b)$. A range of ether core lipids from the methanogenic archaebacterium Methanosarcina barkeri. Biochimica et biophysica acta 875, 487-492.

De Rosa, M., Gambacorta, A., Trincone, A., Basso, A., ZILlIG, W. \& Holz, I. (1987). Lipids of Thermococcus celer, a sulfur-reducing archaebacterium: structure and biosynthesis. Systematic and Applied Microbiology 9, 1-6.

Ferrante, G., Exizl, I. \& Sprott, G. D. (1987). Structure of diether lipids of Methanospirillum hungatei containing novel head group $\boldsymbol{N}, \boldsymbol{N}$-dimethyl amino and $N, N, N$, -trimethyl amino pentanetetrol. Biochimica et biophysica acta 921, 281-291

Grant, W. D., Pinch, G., Harris, J. E., De Rosa, M. \& Gambacorta, A. (1985). Polar lipids in methanogen taxonomy. Journal of General Microbiology 131, 3277-3286.

Kramer, J. K. G., SAUER, F. D. \& BlackWell, B. A. (1987). Structure of two new amino lipids from Methanobacterium thermoautotrophicum. Biochemical Journal 245, 139-143.

Kushwaha, S. G., Kates, M., Sprott, G. D. \& SMrth, I. C. P. (1981). Novel polar lipids from the methanogen Methanospirillum hungatei GP1. Biochimica et biophysica acta 664, 156-173.

LaNGWORTHY, T. A. \& POND, J. L. (1986). Archaebacterial ether lipids and chemotaxonomy. Systematic and Applied Microbiology 7, 253-257.

Maxula, R. A. \& Singer, M. E. (1978). Ethercontaining lipids of methanogenic bacteria. Biochemical and Biophysical Research Communications 82, 716-722.
Minnikin, D. E., Collins, M. D. \& Goodfellow, M. (1979). Fatty acid and polar lipid composition in the classification of Cellulomonas, Oerskovia and related taxa. Journal of Applied Bacteriology 47, 87-95.

MoriI, H., Nishihara, M. Ohga, M. \& Koga, Y. (1986). A diphytanyl ether analogue of phosphatidylserine from a methanogenic bacterium Methanobrevibacter arboriphilus. Journal of Lipid Research 27, 724-730.

Ross, H. N. M., Grant, W. D. \& Harris, J. E. (1985). Lipids in archaebacterial taxonomy. In Chemical Methods in Systematics, pp. 289-300. Edited by M. Goodfellow \& D. Minnikin. London \& New York: Academic Press.

Stetter, K. O., König, H. \& Stackebrandt, E. (1983). Pyrodictium, a new genus of submarine discshaped sulfur reducing bacteria growing optimally at $105^{\circ} \mathrm{C}$. Systematic and Applied Microbiology 4, 535541 .

Tornabene, T. G. \& Langworthy, T. A. (1979). Diphytanyl and dibiphytanyl ether lipids of methanogenic archaebacteria. Science 203, 51-53.

Zillig, W., Stetter, K. O., SChafer, W., JANEKovic, D., Wunderl, S., Holz, I. \& Palm, P. (1981). Thermoproteales: a novel type of extremely thermoacidophilic archaebacteria isolated from Iceland solfataras. Zentralblatt für Bakteriologie, Parasitenkunde, Infektionskrankheiten und Hygiene (Abteilung I Originale C) 3, 218-227.

Zillig, W., Stetter, K. O., Prangishvilli, P., Shafer, W., Wunderl, S., Janerovic, P., Holtz, J. \& PALM, P. (1982). Desulfurococcaceae, the second family of the extremely thermophilic anaerobic, sulfur-respiring Thermoproteales. In Archaebacteria, pp. 304-317. Edited by $O$. Kandler. Stuttgart: Gustav Fisher Verlag.

Zillig, W., Gierl, A., Shrieber, G., WÜnderl, S., JANekovic, D., Stetter, K. O. \& KLeNK, H. P. (1983). The archaebacterium Thermofilum pendens represents a novel genus of thermophilic anaerobic sulfur-respiring Thermoproteales. Systematic and Applied Microbiology 4, 79-87. 